Article

\title{
Fabrication and Characterization of Capacitive Micromachined Ultrasonic Transducers with Low-Temperature Wafer Direct Bonding
}

\author{
Xiaoqing Wang ${ }^{1,2}$, Yude $\mathrm{Yu}^{1,2, *}$ and Jin Ning ${ }^{2,3}$ \\ 1 State Key Laboratory on Integrated Optoelectronics, Institute of Semiconductors, \\ Chinese Academy of Sciences, Beijing 100083, China; xiaoqingwang@semi.ac.cn \\ 2 University of Chinese Academy of Sciences, Beijing 100049, China \\ 3 Engineering Research Center for Semiconductor Integrated Technology, Institute of Semiconductors, \\ Chinese Academy of Sciences, Beijing 100083, China; ningjin@semi.ac.cn \\ * Correspondence: yudeyu@semi.ac.cn; Tel.: +86-10-8230-4979
}

Academic Editor: Marc Desmulliez

Received: 31 October 2016; Accepted: 6 December 2016; Published: 11 December 2016

\begin{abstract}
This paper presents a fabrication method of capacitive micromachined ultrasonic transducers (CMUTs) by wafer direct bonding, which utilizes both the wet chemical and $\mathrm{O}_{2}$ plasma activation processes to decrease the bonding temperature to $400{ }^{\circ} \mathrm{C}$. Two key surface properties, the contact angle and surface roughness, are studied in relation to the activation processes, respectively. By optimizing the surface activation parameters, a surface roughness of $0.274 \mathrm{~nm}$ and a contact angle of $0^{\circ}$ are achieved. The infrared images and static deflection of devices are assessed to prove the good bonding effect. CMUTs having silicon membranes with a radius of $60 \mu \mathrm{m}$ and a thickness of $2 \mu \mathrm{m}$ are fabricated. Device properties have been characterized by electrical and acoustic measurements to verify their functionality and thus to validate this low-temperature process. A resonant frequency of $2.06 \mathrm{MHz}$ is obtained by the frequency response measurements. The electrical insertion loss and acoustic signal have been evaluated. This study demonstrates that the CMUT devices can be fabricated by low-temperature wafer direct bonding, which makes it possible to integrate them directly on top of integrated circuit (IC) substrates.
\end{abstract}

Keywords: capacitive micromachined ultrasonic transducers (CMUTs); low temperature wafer direct bonding; contact angle; surface roughness

\section{Introduction}

Ultrasonic transducers are widely used in medical imaging, gas-flow metering, industrial cleaning and non-destructive testing. In many areas of application, capacitive micromachined ultrasonic transducers (CMUTs) have been considered an attractive alternative to conventional piezoelectric transducers [1-3]. CMUTs can be batch produced with photolithography and other mature techniques in semiconductor industries, which is difficult with piezoelectric transducers [4]. Therefore, CMUTs have a great potential for monolithic integration, which presents multiple benefits such as a reduced system footprint, lower interconnection parasitic capacitance and simplified packing. Moreover, CMUTs provide advantages in size reduction and easier transducer array fabrication [5].

Considerable research on CMUTs has been conducted in recent decades [6-8]. To produce such a CMUT device, two main fabrication methods are currently adopted: surface micromachining [9] or wafer bonding [10]. Surface micromachining CMUTs is a technique where the cavity underneath the membrane is created by depositing a sacrificial layer on the substrate. After the membrane deposition, the sacrificial layer is removed with etchant [11]. However, the surface micromachining process sets 
limitations on the cavity and membrane size because of sticking problems that occur during the releasing step. Moreover, releasing the membranes is difficult due to large capillary forces and may introduce contamination in the cavity, which decreases the success rate of the device [12].

In the wafer bonding process, membranes are fabricated by utilizing silicon on insulator (SOI) wafers or thin silicon wafers [13]. This process adds many design flexibilities and also offers wide material choices. Because the membrane and the cavity are made on separate wafers, it is possible to optimize them both simultaneously. The technique reduces the number of process steps, which increases the control of the fabrication procedure. In addition, there are no wet-release processes to limit the size of the membranes, allowing the fabrication of CMUTs for a wide range of frequencies $[13,14]$. Nevertheless, conventional wafer bonding technology requires high temperature $\left(>1000{ }^{\circ} \mathrm{C}\right)$ to ensure good bonding quality, which prohibits monolithic integration of CMUTs [15]. Additionally, a high temperature could result in the degradation of thermally sensitive devices and residual stress in processed silicon wafers with different thermal expansion coefficients [16]. To avoid the problems mentioned above, low-temperature wafer bonding which is limited to $400{ }^{\circ} \mathrm{C}$ is strongly desirable. Many efforts have been made to reduce the bonding temperature. One approach is to deposit the adhesion material such as titanium and gold, which migrates into silicon at low temperatures [17]. However, this method could bring pollution caused by the adhesion material. Another approach to decrease the temperature is to employ low-temperature wafer direct bonding technology, which is enabled by using activation processes of the surfaces. Such a process consists of wet chemical activation or $\mathrm{O}_{2}$ plasma treatment prior to bonding $[18,19]$. With these surface activation techniques, less energy is required during the thermal annealing steps and they achieve good bonding quality at low temperatures.

In this paper, we report a method to fabricate CMUTs with low-temperature wafer direct bonding at $400{ }^{\circ} \mathrm{C}$. The wet chemical and $\mathrm{O}_{2}$ plasma activation processes are employed together. The influences on the surface roughness and water contact angle of the activation treatments are investigated. The low-temperature CMUT fabrication process has been presented in detail. Both electrical and acoustic characteristics of the fabricated devices are measured and discussed.

\section{Surface Properties by Activation Processes}

\subsection{Contact Angle}

The main mechanism of wafer direct bonding at low temperature is to activate the surfaces by creating more hydroxyl $(\mathrm{OH})$ groups, which results in higher hydrophilicity. Two methods of surface activation are utilized: wet chemical and $\mathrm{O}_{2}$ plasma activations. The wet chemical activation is usually achieved by treating pre-bonding wafers with various reagent combinations to activate the surfaces. $\mathrm{O}_{2}$ plasma activation is a process of applying $\mathrm{O}_{2}$ plasma treatment to improve the hydrophilicity of the surfaces.

To investigate the surface hydrophilicity of wafers in practical activation conditions, we measured the contact angle by a drop shape analysis system (DSA100, KRÜSS, Hamburg, Germany). The contact angle is critical to evaluating the hydrophilicity of the surfaces and a lower contact angle means a higher hydrophilicity, which could improve the bonding effect of micro-electromechanical systems (MEMS) and system integration. We measured the contact angles immediately after the wet and oxygen treatments. If the wafers were stored in a normal clean room environment, the contact angle showed no obvious change when the elapsed time was less than $30 \mathrm{~min}$ after the wet and oxygen treatment. After $30 \mathrm{~min}$, the contact angle changed significantly over time. The contact angle of as-received $\mathrm{Si}$ covered with $\mathrm{SiO}_{2}$ without any treatment is $49.5^{\circ}$, as shown in Figure 1a. The RCA clean is a procedure developed by Werner Kern at RCA (Radio Corporation of America) laboratories for processing wafers in the late 1960's. Then, the wafer was cleaned by $\mathrm{H}_{2} \mathrm{SO}_{4} / \mathrm{H}_{2} \mathrm{O}_{2}\left(\mathrm{H}_{2} \mathrm{SO}_{4}: \mathrm{H}_{2} \mathrm{O}_{2}=3: 1\right)$, a modified RCA1 $\left(\mathrm{H}_{2} \mathrm{O}: \mathrm{H}_{2} \mathrm{O}_{2}: \mathrm{NH}_{4} \mathrm{OH}=5: 1: 0.2\right)$, a modified RCA2 $\left(\mathrm{H}_{2} \mathrm{O}: \mathrm{H}_{2} \mathrm{O}_{2}: \mathrm{HCl}=5: 1: 0.2\right)$ and $\mathrm{HNO}_{3} / \mathrm{H}_{2} \mathrm{O} / \mathrm{HF}\left(\mathrm{HNO}_{3}: \mathrm{H}_{2} \mathrm{O}: \mathrm{HF}=1: 20: 2 \times 10^{-4}\right)$ solutions. The contact angle is $17.3^{\circ}$, as shown in 
Figure 1b. It is observed that the contact angle is obviously lower than that of the as-received wafer, which demonstrates the wet chemical activation could improve the hydrophilicity of surfaces.

In order to analyze the effects of $\mathrm{O}_{2}$ plasma activation, we measured two sets of wafers. One set was only activated with $\mathrm{O}_{2}$ plasma. The other set was processed with wet chemical and $\mathrm{O}_{2}$ plasma activations at the same time. The different plasma activation times selected were 15, 30, 60, 150, 300 and $600 \mathrm{~s}$. The contact angles after $\mathrm{O}_{2}$ plasma activation for different times are shown in Figure 2. The experimental error is $\pm 1.6^{\circ}$. For the wafer treated only with $\mathrm{O}_{2}$ plasma, the contact angle drops with the increase of the activation time. When the activation time is less than $30 \mathrm{~s}$, the contact angle is slightly decreased. Then, the contact angle decreases significantly as the activation time increases from 30 to $300 \mathrm{~s}$. After $300 \mathrm{~s}$, the decrease of the contact angle is not obvious. This may be explained by the $\mathrm{O}_{2}$ plasma removing the organic contaminants and reacting with the surface very little during a short activation time. At a higher activation time, $\mathrm{O}_{2}$ plasma starts to react with the surface and create more dangling bonds. When the activation time is higher than $300 \mathrm{~s}$, the dangling bonds on the surface become saturated and the contact angle decreases slowly. For the wafer treated with both wet chemical and $\mathrm{O}_{2}$ plasma activations, the contact angle decreases with the increase of the activation time immediately. At $30 \mathrm{~s}$, the contact angle is $0^{\circ}$ and there is no change with the increase of the activation time. These results indicate that activating the surfaces with wet chemical and $\mathrm{O}_{2}$ plasma processes simultaneously can result in better hydrophilicity, which could obtain a good bonding quality in device fabrication.

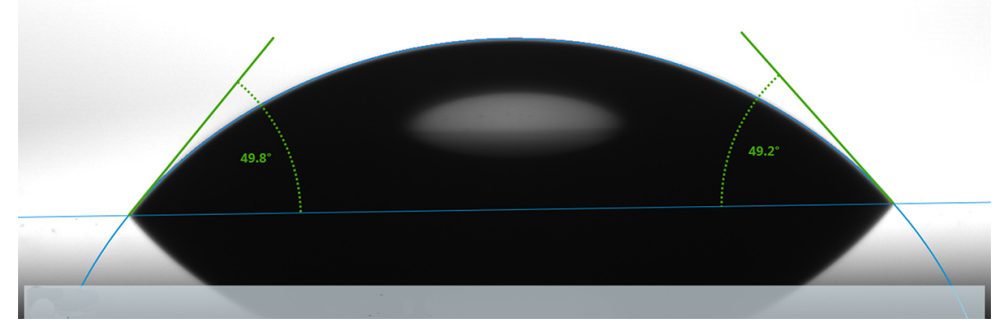

(a)

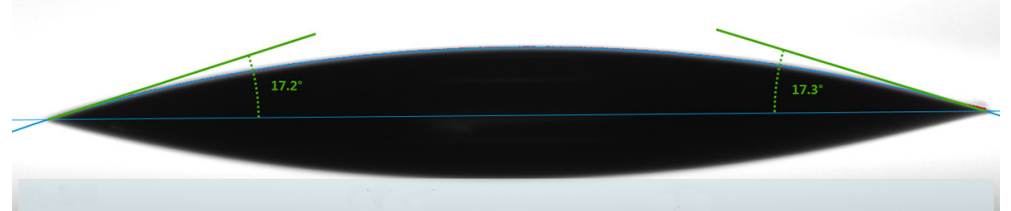

(b)

Figure 1. (a) The contact angle of as-received wafer; (b) The contact angle with the wet chemical activation process.

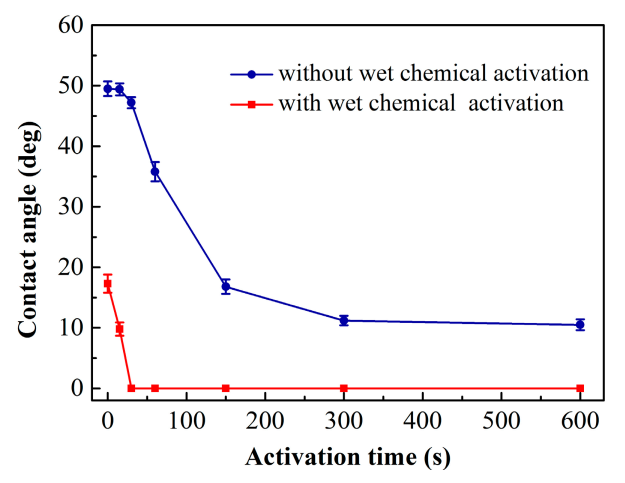

Figure 2. Contact angle as a function of $\mathrm{O}_{2}$ plasma activation time. 


\subsection{Surface Roughness}

When two wafers bond over the entire area, the surface roughness is a key factor to achieving a high bonding quality. Lower surface roughness allows a greater contact area between bonding surfaces. Therefore, surface roughness plays an important role in the adhesion quality in CMUT devices. In our work, the surface roughness was measured using atomic force microscopy (AFM D3100, Veeco, Santa Barbara, CA, USA) in standard tapping mode with a scan area of $5 \mu \mathrm{m} \times 5 \mu \mathrm{m}$. The root mean square (RMS) method was used to evaluate the surface roughness $\left(R_{\mathrm{q}}\right)$. The surface roughness of the as-received $\mathrm{Si}$ substrate covered with $\mathrm{SiO}_{2}$ is $0.199 \mathrm{~nm}$, as shown in Figure 3a. After the dry etching process for the cavity, the surface roughness increased to $0.293 \mathrm{~nm}$, as shown in Figure $3 \mathrm{~b}$. This may be explained by the photoresist and reactive ion etching during the fabrication process possibly roughening the wafer surface. Then, the wafer was treated with $\mathrm{O}_{2}$ plasma. The RMS surface roughness of the wafer as a function of activation time is shown in Figure 4. The experimental error is $\pm 0.005 \mathrm{~nm}$. It can be seen that the surface roughness decreases with the increase of the activation time until $60 \mathrm{~s}$, at which time the surface roughness is $0.274 \mathrm{~nm}$. Such a smoothing effect is attributed to the surface cleaning of particles and hydrocarbons by the $\mathrm{O}_{2}$ plasma treatment. After an activation time of $60 \mathrm{~s}$, the surface roughness increases significantly with the increasing treatment time. When the $\mathrm{O}_{2}$ plasma is used to treat the wafers, it starts etching as well as oxidizing the surfaces. However, the rate of etching is higher than that of oxidation at higher activation times. It indicates that excessive plasma activation could result in more surface damage. The $\mathrm{O}_{2}$ plasma activation time of $60 \mathrm{~s}$ is suitable for direct bonding due to the lower surface roughness. The benefit is that it reduces the annealing temperature required to achieve a strong bond in the following CMUTs fabrication.

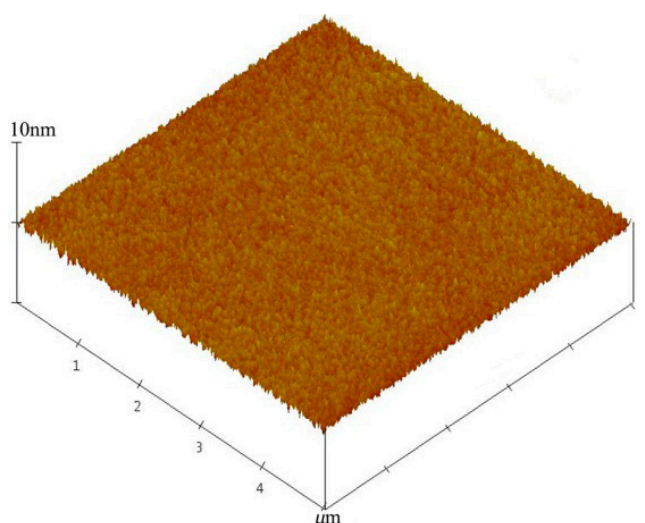

(a)

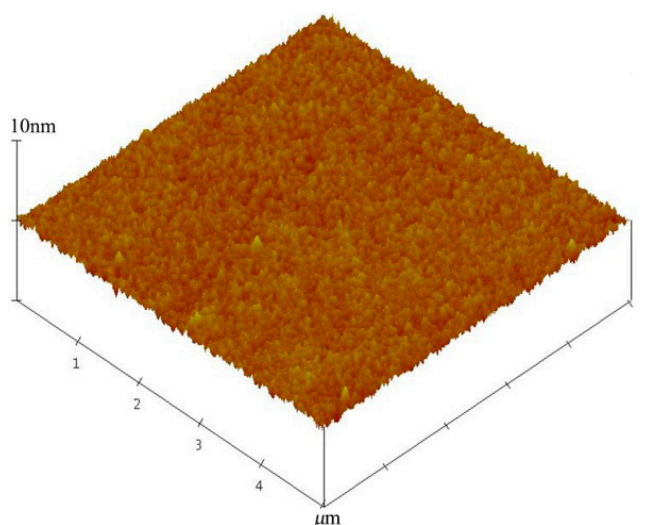

(b)

Figure 3. Three-dimensional (3D) atomic force microscopy (AFM) images of wafer surfaces. (a) Root mean square (RMS) of as-received wafer is $0.199 \mathrm{~nm}$; (b) RMS after etching for cavity is $0.293 \mathrm{~nm}$.

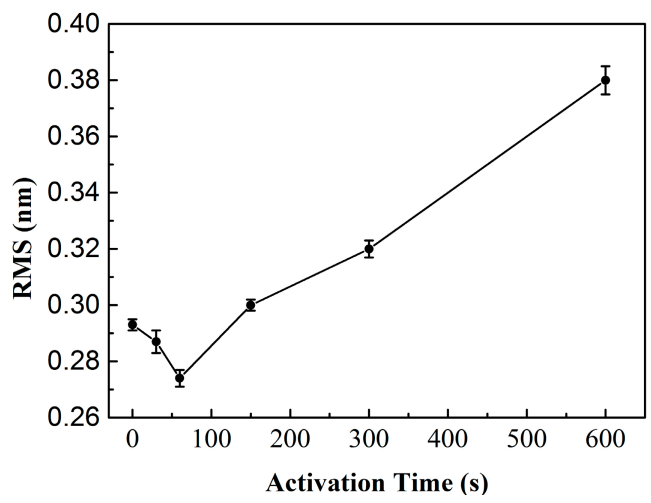

Figure 4. Surface roughness as a function of $\mathrm{O}_{2}$ plasma activation time. 


\section{Low-Temperature CMUT Fabrication Process}

Basically, a CMUT cell can be considered as a parallel plate capacitor composed of a membrane suspended above a cavity. When a direct current (DC) voltage is applied between the bottom electrode and the top electrode, the membrane deflects toward the substrate due to the electrostatic force. The electrostatic force is balanced by a restoring mechanical force which is derived from the increased strain in the membrane. The membrane can vibrate to generate the ultrasound by adding an alternating current $(\mathrm{AC})$ voltage on top of the DC bias voltage. Then the mechanical energy is coupled into the surrounding medium. The dimensions and material properties determine the dynamic behavior and frequency characteristics of the CMUT. The specific parameters of a designed structural element are listed in Table 1.

Table 1. The parameters of the designed capacitive micromachined ultrasonic transducer (CMUT) structure.

\begin{tabular}{cc}
\hline Parameters & Value \\
\hline Membrane radius $(\mu \mathrm{m})$ & 60 \\
Membrane thickness $(\mu \mathrm{m})$ & 2 \\
Electrode radius $(\mu \mathrm{m})$ & 30 \\
Electrode thickness $(\mu \mathrm{m})$ & 0.3 \\
Number of cells & 256 \\
Insulation layer thickness $(\mu \mathrm{m})$ & 0.2 \\
Cavity depth $(\mu \mathrm{m})$ & 0.6 \\
\hline
\end{tabular}

The process flow to fabricate a CMUT is shown in Figure 5. Each cell was designed to be a circle shape with a $60-\mu \mathrm{m}$-radius membrane and all are electrically connected in parallel. Fabrication began on a 4 in (100) conductive silicon wafer covered with a $800 \mathrm{~nm}$ thermal silicon dioxide layer, as illustrated in Figure 5a. The silicon wafer was doped to achieve high conduction, which was used as the bottom electrode in the CMUT. Then the cavity was formed by patterning the thermal silicon oxide layer, as shown in Figure 5b. We used an SOI wafer with a device layer thickness of $2 \mu \mathrm{m}$, which defined the membrane thickness. The device layer of the SOI is made of single crystal silicon, which has low internal stress and well-defined material parameters: Young's modulus $(E)$, Poisson's ratio $(\sigma)$ and density $(\rho)$. The SOI wafer was bonded to the substrate with the goal to transfer the device layer to the substrate. Before wafer direct bonding, both the SOI wafer and processed substrate were treated by wet chemical and $\mathrm{O}_{2}$ plasma activations. The wafers were first cleaned by acetone, ethanol, and $\mathrm{H}_{2} \mathrm{SO}_{4} / \mathrm{H}_{2} \mathrm{O}_{2}$ solutions followed by a de-ionized (DI) water rinse. Next, modified RCA1 and RCA2 solutions were used to process the wafers for $30 \mathrm{~min}$ at $70-80^{\circ} \mathrm{C}$. After rinsing in DI water, the wafers were immersed in an $\mathrm{HNO}_{3} / \mathrm{H}_{2} \mathrm{O} / \mathrm{HF}$ mixture for about $3 \mathrm{~min}$ at $70-80{ }^{\circ} \mathrm{C}$ followed by rinsing in DI water and blow drying. Thereafter, both wafers were activated by $\mathrm{O}_{2}$ plasma at $200 \mathrm{~W}$ for $60 \mathrm{~s}$.

After the wet chemical and $\mathrm{O}_{2}$ plasma activations, both wafers were brought into contact and annealed in a commercial wafer bonder (Suss SB6e) at $400{ }^{\circ} \mathrm{C}$ with 3000 mbar pressure for $2 \mathrm{~h}$ in vacuum $\left(<10^{-4} \mathrm{mbar}\right)$, as indicated in Figure $5 \mathrm{c}$. After completion of the bonding process, the handle layer of the bonded SOI wafer was removed by a tetramethylammonium hydroxide (TMAH) solution at $80{ }^{\circ} \mathrm{C}$. In this step, the buried oxide layer provided a TMAH etch stop. The buried oxide layer was then removed in a buffered hydrofluoric acid (BHF) solution that stopped on the silicon surface, as shown in Figure 5d. This completed the membrane fabrication. Subsequently, the membrane was patterned by the photolithography and dry etching step to open a hole through the top layer to contact the bottom electrode of the CMUT, as illustrated in Figure 5e. For electrical connection, aluminum was sputtered by a metal sputter system and patterned to serve as the top and bottom electrodes by lift-off technology, as shown in Figure $5 \mathrm{f}$. 


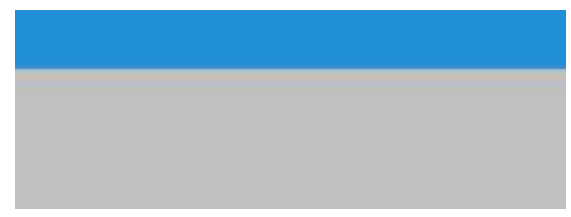

(a)

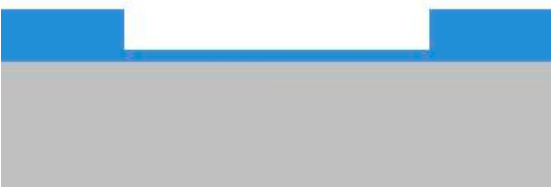

(b)

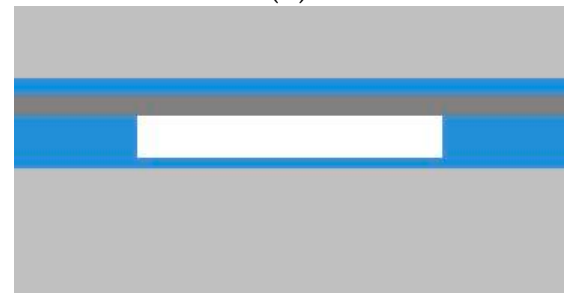

(c)

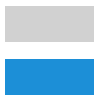

Low resistivity $\mathrm{Si}$

Silicon oxide

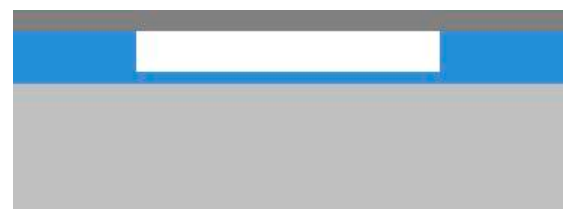

(d)

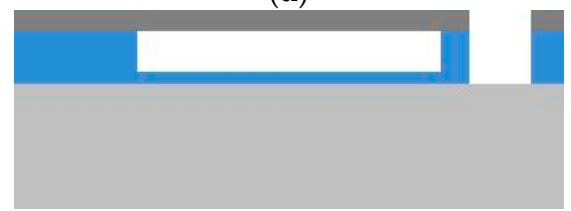

(e)

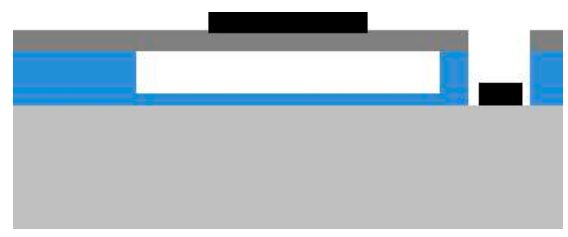

(f)

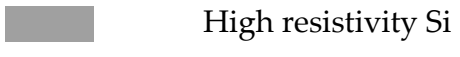

$\mathrm{Al}$

Figure 5. Process flow of micromachined ultrasonic transducer (CMUT) fabrication. (a) Thermal oxidation; (b) Dry etching for cavity; (c) Wafer bonding for the substrate with silicon on insulator (SOI); (d) Removing the silicon substrate and the buried oxide of the SOI; (e) Silicon and oxide etching for ground contact; (f) Aluminum deposition for the top and bottom electrodes.

In order to inspect the bonding interface under the membrane, the designed devices were observed by an infrared imaging system. It can be seen that there is no damage or falling off of the membranes and electrodes, as shown in Figure 6. No voids or holes are formed in the bonding area. The wafers are strongly bonded to withstand the subsequent removal of the SOI handle layer and buried oxide layer in the wet etching processes. Because the cavity beneath the membrane was considered vacuum-sealed, the membrane deflected under atmospheric pressure. We measured the static deflection along the CMUT width though the center of the membrane in the atmospheric environment by AFM, as shown in Figure 7. A center displacement of $125.15 \mathrm{~nm}$ is observed as expected, which indicates good vacuum sealing of the cavity. These results demonstrate the good bonding quality and prove the feasibility of the low-temperature fabrication process of CMUTs.

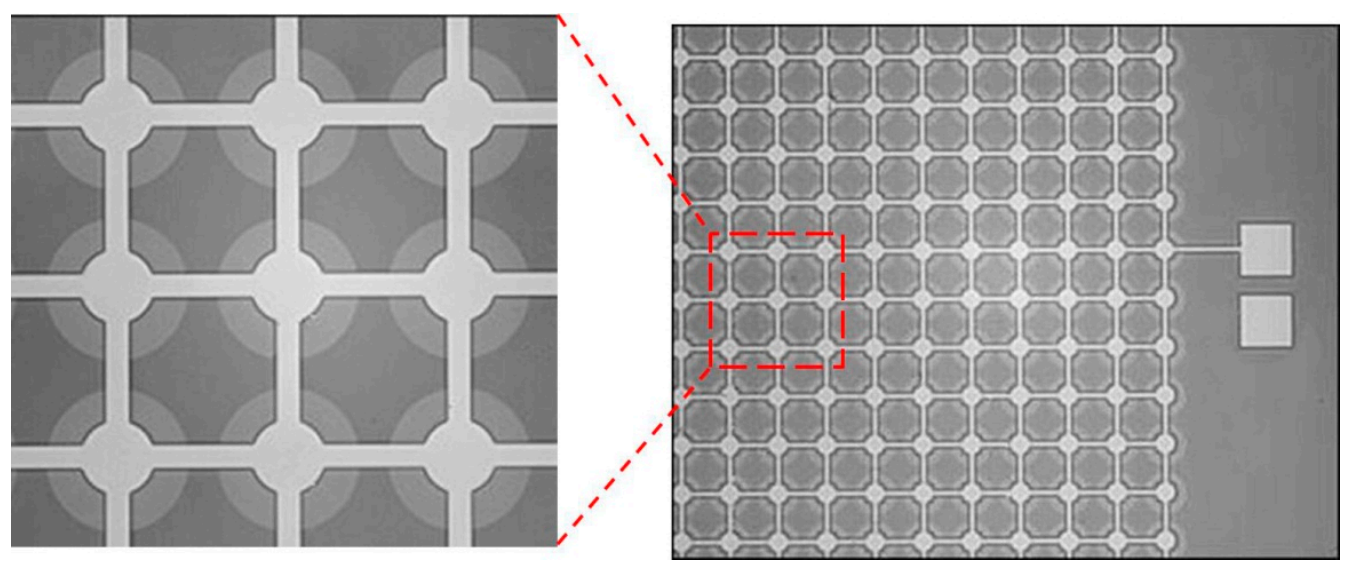

Figure 6. The infrared images of CMUT array. 


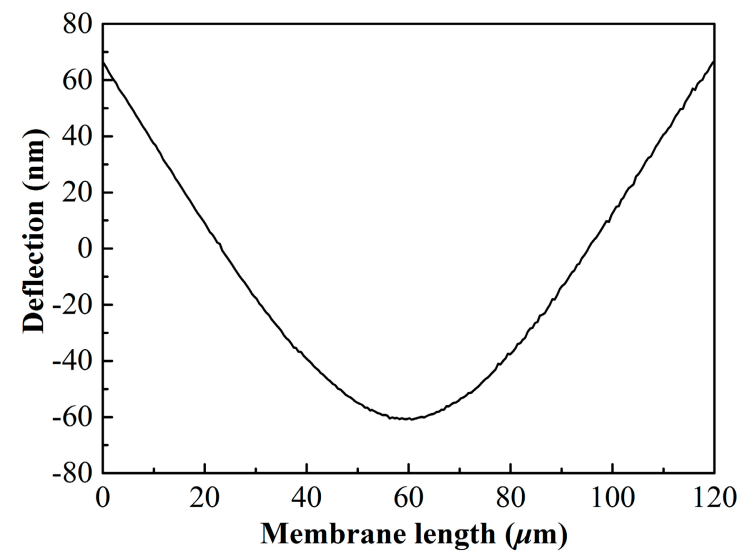

Figure 7. Static deflection profile measured along the CMUT width though the center of the membrane under atmospheric pressure.

\section{Device Characterizations}

In order to verify the functionality and properties of the CMUT, the fabricated device was characterized by electrical and acoustic measurements. We measured the electromechanical response of the CMUT using a Polytec laser vibrometer. In this mode, the resonance frequency of $2.06 \mathrm{MHz}$ was obtained without the DC bias voltage. When applying the DC bias voltage from 10 to $30 \mathrm{~V}$ with an AC voltage of $1 \mathrm{~V}_{\mathrm{pp}}$ between the electrodes, the peak center deflection as a function of frequency is shown in Figure 8. The excitation frequency was tuned from 1.90 to $2.20 \mathrm{MHz}$ in order to detect the resonance frequency, at which the peak center deflection was maximized. For the $30 \mathrm{~V}$ DC bias voltage, the $-3 \mathrm{~dB}$ bandwidth is $11 \mathrm{kHz}$, leading to the $Q$-factor of 187 . The resonant peak shifts towards lower frequencies with the increase of the DC bias voltage, while the vibration amplitude increases significantly. This phenomenon is caused by the nonlinearity of electromechanical interaction, and is called the spring softening effect which is common to all MEMS devices actuated with electrostatic forces.

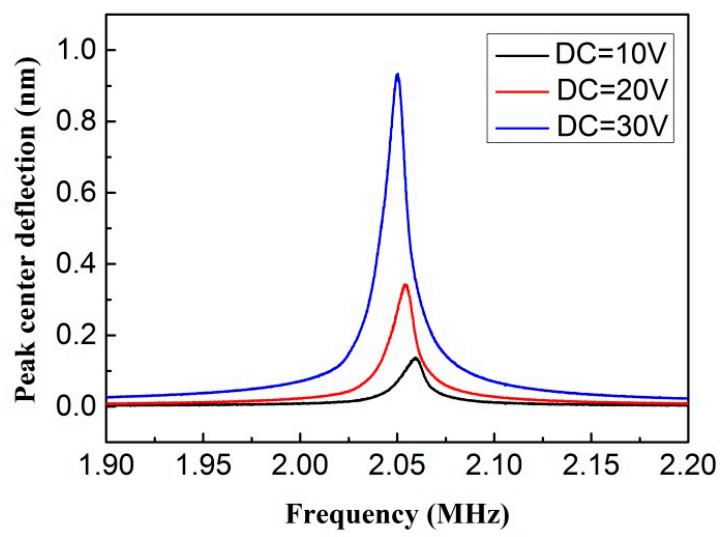

Figure 8. Peak center deflection as a function of frequency for CMUT at different DC levels with an AC voltage of $1 \mathrm{~V}_{\mathrm{pp}}$ in air.

The basic building block of the CMUT resonator is a circular plate, which resonates in the first flexural mode. The dimensions and the material properties of the circular plate determine the resonant frequency $f_{0}$, as:

$$
f_{0}=0.47 \frac{t}{a^{2}} \sqrt{\frac{E}{\rho\left(1-v^{2}\right)}}
$$


where $\rho, a, t, E$ and $v$ are the density, radius, thickness, Young's modulus and Poisson's ratio of the membrane, respectively [20]. Based on this equation, the theoretical resonance frequency was $2.03 \mathrm{MHz}$. It can be observed the measured resonant frequency is in good agreement with the theoretical result, indicating that the stresses in the membrane and the fabrication process are well-controlled. There was a difference of only approximately $1 \%$ between the measured resonant frequency and the theoretical value. As for the device structure, the membrane thickness has a significant impact on the resonance frequency of the device. Any membrane thickness deviations from the theoretical value could result in a variation in the measured frequency. Additionally, there may be discrepancies between the design and fabricated dimensions of the membranes in the lithography and etching process, which could also lead to disparities of the frequencies.

In addition, the electrical insertion loss $\left(S_{21}\right)$ of the CMUT transducer was measured in air. A vector network analyzer (E5071C, Agilent Technologies, Palo Alto, CA, USA) and a DC supply (U8032A, Agilent Technologies, Palo Alto, CA, USA) were used. The vector network analyzer was connected to the CMUT through a capacitor that blocked the DC voltage, but allowed the AC signal to pass. The DC bias voltage was supplied through a resistor to provide a DC voltage across the transducer. For a $10 \mathrm{~V}$ DC bias voltage and $0.2 \mathrm{~V} \mathrm{AC}$ voltage, a resonance peak at about $2.06 \mathrm{MHz}$ is observed and the $S_{21}$ is $-24 \mathrm{~dB}$ as shown in Figure 9a. In order to further assess the acoustic transmission characterization of CMUTs, we tested the transducer in a water tank with a needle hydrophone (PT-1609344, Institute of Acoustics, UCAS, Beijing, China). The transducer was $0.25 \mathrm{~cm}^{2}$ to increase the acoustic pressure. It was excited with 20 cycle burst sine signal of $20 \mathrm{~V}_{\mathrm{pp}}$ at $2.06 \mathrm{MHz}$. The hydrophone was placed at the center line of the CMUTs with a distance of $10 \mathrm{~mm}$ to receive the sound wave, as seen in Figure $9 \mathrm{~b}$. The sound pressure of the transducer is $4.3 \mathrm{kPa}$ with the $0.6 \mu \mathrm{V} / \mathrm{Pa}$ receive sensitivity of the hydrophone at 2.06 MHz. A $6.7 \mu$ s time of flight was measured by comparing the time elapsed between the actuated signal and the received signal. Using the traveled distance and time of flight, the velocity of the ultrasonic wave can be calculated to be $1493 \mathrm{~m} / \mathrm{s}$ in accordance with the well-known speed of sound in water, which is preliminary evidence of the acoustic properties of CMUTs.

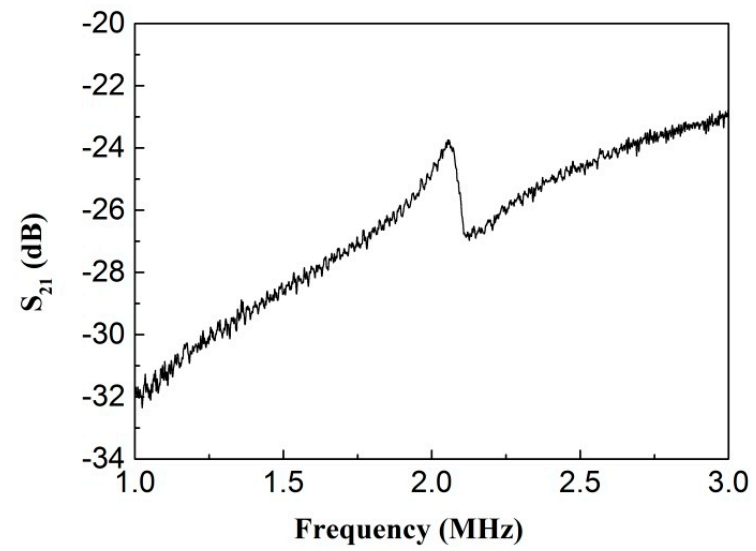

(a)

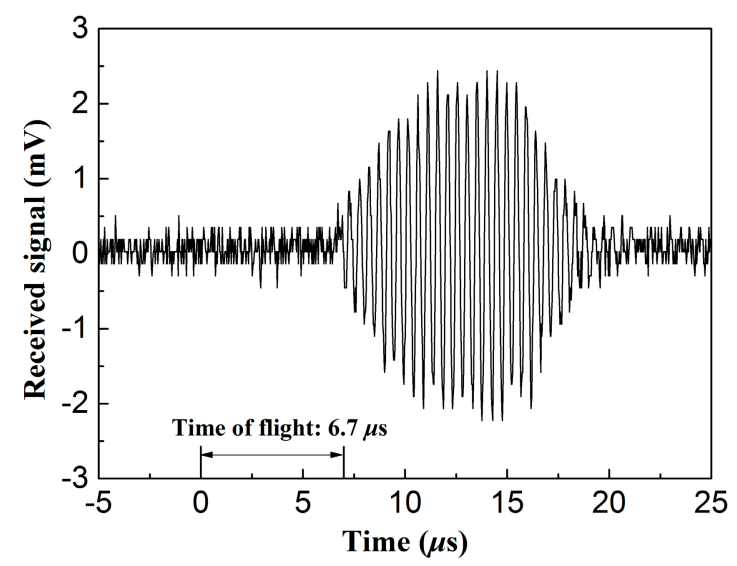

(b)

Figure 9. (a) Electrical insertion loss $\left(S_{21}\right)$ for CMUT; (b) Received signal actuated by 20 cycle burst sine signal.

For the performance of CMUTs made in the way we describe, the $Q$-factor is 187, which is higher than that presented in [21] ( $Q$-factor of 31.5) or [22] ( $Q$-factor of 150). In addition, the difference between the measured resonant frequency and the theoretical resonant frequency is only about $1 \%$. This value is smaller than that of the CMUTs achieved in [23], which has a difference of about $6 \%$ between these two values. Thirdly, the electrical insertion loss $\left(S_{21}\right)$ is about $-24 \mathrm{~dB}$, which is better than that of $-42 \mathrm{~dB}$ presented in [24]. Finally, we measured the acoustic pressure of $4.3 \mathrm{kPa}$ for 256 cells. 
As shown in [25], the acoustic pressure is $8.2 \mathrm{kPa}$ for 2708 cells. These measurements indicate that CMUTs made in the way we describe have a good performance.

\section{Conclusions}

In this paper, CMUTs have been successfully fabricated by the wafer direct bonding process at $400{ }^{\circ} \mathrm{C}$. Our studies have focused on activation methods in order to satisfy this temperature specification. These studies indicated that using the wet chemical and $\mathrm{O}_{2}$ plasma treatment simultaneously has good activation effects to achieve the low-temperature wafer direct bonding. The surface roughness and contact angle were investigated to acquire an optimized bonding process. The contact angle of $0^{\circ}$ was obtained by this process. The surface roughness decreased with the $\mathrm{O}_{2}$ plasma activation time until $60 \mathrm{~s}$ and then increased significantly, which indicated the activation time of $60 \mathrm{~s}$ was suitable for bonding. The infrared images and static deflection at atmospheric pressure have been evaluated to prove the good bonding effect.

To verify the validity of the process and to determine the properties of the CMUTs, the device was characterized by electrical and acoustic measurements. The resonance frequency of the CMUT at $2.06 \mathrm{MHz}$ in air was measured. A spring softening effect was clearly observed, exhibiting expected characteristics. The measured electrical insertion loss of the CMUT was presented. The transducers were tested in water in order to determine the CMUT acoustic transmission behavior. These analyses demonstrated the functionality of the implemented CMUTs fabricated by the low-temperature process. This low-temperature fabrication technology will enable the integration of CMUTs directly above integrated circuit (IC) for feasible, highly compact ultrasonic systems, resulting in a smaller size, lower power and higher performance.

Acknowledgments: The authors gratefully acknowledge the Key Program of the National Natural Science Foundation of China (Grant No. 61334008) and the National Natural Science Foundation of China support (Grand No. 61376072).

Author Contributions: Xiaoqing Wang, Yude Yu and Jin Ning conceived and designed the experiments; Xiaoqing Wang performed the experiments; Xiaoqing Wang, Yude Yu and Jin Ning analyzed the data; Xiaoqing Wang wrote the paper; Xiaoqing Wang, Jin Ning and Yude Yu revised the paper. All authors read and approved the final manuscript.

Conflicts of Interest: The authors declare no conflict of interest.

\section{References}

1. Oralkan, Ö.; Ergun, A.S.; Johnson, J.A.; Karaman, M.; Demirci, U.; Kaviani, K.; Lee, T.H.; Khuri-Yakub, B.T. Capacitive micromachined ultrasonic transducers: Next-generation arrays for acoustic imaging? IEEE Trans. Ultrason. Ferroelectr. Freq. Control 2002, 49, 1596-1610. [CrossRef] [PubMed]

2. Khuri-Yakub, B.T.; Oralkan, Ö. Capacitive micromachined ultrasonic transducers for medical imaging and therapy. J. Micromech. Microeng. 2011, 21, 054004-054014. [CrossRef] [PubMed]

3. Zhang, W.; Zhang, H.; Jin, S.J.; Zeng, Z.M. An analytical model for CMUTs with square multilayer membranes using the Ritz method. Micromachines 2016, 7, 55-74. [CrossRef]

4. Gurun, G.; Tekes, C.; Zahorian, J.; Xu, T.; Satir, S.; Karaman, M.; Hasler, J.; Degertekin, F.L. Single-chip CMUT-on-CMOS front-end system for real-time volumetric IVUS and ICE imaging. IEEE Trans. Ultrason. Ferroelectr. Freq. Control 2014, 61, 239-250. [CrossRef] [PubMed]

5. Ergun, A.S.; Huang, Y.L.; Zhuang, X.F.; Oralkan, Ö.; Yarahoğlu, G.G.; Khuri-Yakub, B.T. Capacitive micromachined ultrasonic transducers: Fabrication technology. IEEE Trans. Ultrason. Ferroelectr. Freq. Control 2005, 52, 2242-2258. [PubMed]

6. Bagolini, A.; Savoia, A.S.; Picciotto, A.; Boscardin, M.; Bellutti, P.; Lamberti, N.; Caliano, G. PECVD low stress silicon nitride analysis and optimization for the fabrication of CMUT devices. J. Micromech. Microeng. 2015, 25, 15012-15023. [CrossRef]

7. Jeong, B.G.; Kim, D.K.; Hong, S.W.; Chung, S.W.; Shin, H.J. Performance and reliability of new CMUT design with improved efficiency. Sens. Actuators A Phys. 2013, 199, 325-333. [CrossRef] 
8. Zhang, P.Y.; Fitzpatrick, G.; Harrison, T.; Moussa, W.A.; Zemp, R.J. Double-SOI wafer-bonded CMUTs with improved electrical safety and minimal roughness of dielectric and electrode surfaces. J. Microelectromech. Syst. 2012, 21, 668-680. [CrossRef]

9. Ladabaum, I.; Jin, X.C.; Soh, H.T.; Atalar, A.; Khuri-Yakub, B.T. Surface micromachined capacitive ultrasonic transducers. IEEE Trans. Ultrason. Ferroelectr. Freq. Control 1998, 45, 678-690. [CrossRef] [PubMed]

10. Huang, Y.L.; Ergun, A.S.; Häggström, E.; Badi, M.H.; Khuri-Yakub, B.T. Fabricating capacitive micromachined ultrasonic transducers with wafer-bonding technology. J. Microelectromech. Syst. 2003, 12, 128-137. [CrossRef]

11. Belgacem, B.; Alquier, D.; Muralt, P.; Baborowski, J.; Lucas, S.; Jerisian, R. Optimization of the fabrication of sealed capacitive transducers using surface micromachining. J. Micromech. Microeng. 2004, 14, $299-304$. [CrossRef]

12. Salim, M.S.; AdbMalek, M.F.; Heng, R.B.W.; Juni, K.M.; Sabri, N. Capacitive micromachined ultrasonic transducers: Technology and application. J. Med. Ultrasound 2012, 20, 8-31. [CrossRef]

13. Huang, Y.L.; Zhuang, X.F.; Haeggstrom, E.O.; Ergun, A.S.; Cheng, C.H.; Khuri-Yakub, B.T. Capacitive micromachined ultrasonic transducers (CMUTs) with isolation posts. Ultrasonics 2008, 48, 74-81. [CrossRef] [PubMed]

14. Wygant, I.O.; Kupnik, M.; Windsor, J.C.; Wright, W.M.; Wochner, M.S.; Yaralioglu, G.G.; Hamilton, M.F.; Khuri-Yakub, B.T. Capacitive micromachined ultrasonic transducers for generation of highly directional sound with a parametric array. IEEE Trans. Ultrason. Ferroelectr. Freq. Control 2009, 56, 193-203. [CrossRef] [PubMed]

15. Park, K.K.; Lee, H.; Kupnik, M.; Khuri-Yakub, B.T. Fabrication of capacitive micromachined ultrasonic transducers via local oxidation and direct wafer bonding. J. Microelectromech. Syst. 2011, 20, 95-103. [CrossRef]

16. Kowal, J.; Nixon, T.; Aitken, N.; Braithwaite, N.S.J. Surface activation for low temperature wafer fusion bonding by radicals produced in an oxygen discharge. Sens. Actuators A Phys. 2009, 155, 145-151. [CrossRef]

17. Tsuji, Y.; Kupnik, M.; Khuri-Yakub, B.T. Low temperature process for CMUT fabrication with wafer bonding technique. In Proceedings of the IEEE International Ultrasonics Symposium, San Diego, CA, USA, 11-14 October 2010; pp. 551-554.

18. Tong, Q.-Y.; Gan, Q.; Fountain, G.; Enquist, P.; Scholz, R.; Gösele, U. Fluorine-enhanced low-temperature wafer bonding of native-oxide covered Si wafers. Appl. Phys. Lett. 2004, 85, 3731-3733. [CrossRef]

19. Bengtsson, S.; Amirfeiz, P. Room temperature wafer bonding of silicon, oxidized silicon, and crystalline quartz. J. Electron. Mater. 2000, 29, 909-915. [CrossRef]

20. Wygant, I.O.; Kupnik, M.; Khuri-Yakub, B.T. Analytically calculating membrane displacement and the equivalent circuit model of a circular CMUT cell. In Proceedings of the IEEE Ultrasonics Symposium, Beijing, China, 2-5 November 2008; pp. 2111-2114.

21. Mukhiya, R.; Sinha, A.; Prabakar, K.; Raghuramaiah, M.; Jayapandian, J.; Gopal, R.; Khanna, V.K.; Shekhar, C. Fabrication of capacitive micromachined ultrasonic transducer arrays with isolation trenches using anodic wafer bonding. IEEE Sens. J. 2015, 15, 5177-5184. [CrossRef]

22. Martinussen, H.; Aksnes, A.; Leirset, E.; Engan, H.E. CMUT characterization by interferometric and electric measurements. IEEE Trans. Ultrason. Ferroelectr. Freq. Control 2009, 56, 2711-2721. [CrossRef] [PubMed]

23. Zhang, Q.; Cicek, P.V.; Allidina, K.; Nabki, F.; E1-Gamal, M.N. Surface-micromachined CMUT using low-temperature deposited silicon carbide membranes for above-IC integration. J. Microelectromech. Syst. 2014, 23, 482-493. [CrossRef]

24. Toan, N.V.; Hahng, S.; Song, Y.; Ono, T. Fabrication of vacuum-sealed capacitive micromachined ultrasonic transducer arrays using glass reflow process. Micromachines 2016, 7, 76-84. [CrossRef]

25. Cetin, A.M.; Bayram, B. Diamond-based capacitive micromachined ultrasonic transducers in immersion. IEEE Trans. Ultrason. Ferroelectr. Freq. Control 2013, 60, 414-420. [CrossRef] [PubMed]

(C) 2016 by the authors; licensee MDPI, Basel, Switzerland. This article is an open access article distributed under the terms and conditions of the Creative Commons Attribution (CC-BY) license (http://creativecommons.org/licenses/by/4.0/). 